\title{
Estro Pós-Parto em Ovelhas da Raça Santa Inês ${ }^{1}$
}

Tânia Maria Leal², José Ferreira Nunes ${ }^{3}$, Maria do P. S. C. Bona Nascimento², Hoston Tomás dos Santos Nascimento ${ }^{2}$, Raimundo Bezerra de Araújo Neto ${ }^{2}$

Resumo: Estudou-se o retorno ao estro de 60 pós-parto ovelhas da raça Santa Inês distribuídas em quatro lotes experimentais, cujos critérios foram a oferta ou não de suplementação alimentar para as matrizes e amamentação continua ou controlada para as crias. As ovelhas permaneceram, nos meses de junho a novembro de 2004 e 2005, na Fazenda Experimental da Embrapa Meio-Norte, em Campo Maior-PI, localizada a $4^{\circ} 46^{\prime}$ 59" S e $42^{\circ} 07^{\prime} 20^{\prime \prime} \mathrm{W}$, a $120 \mathrm{~m}$ acima do nível do mar, pluviosidade média anual de $1.200 \mathrm{~mm}$, distribuídos de janeiro a início de maio, temperatura média anual de $27^{\circ} \mathrm{C}$ e umidade relativa média de $70,34 \%$. Usou-se o delineamento experimental inteiramente casualizado em arranjo fatorial $2 \times 2$, com avaliações dos fatores sem suplementação x com suplementação alimentar e amamentação contínua x controlada. As médias e respectivos desvios-padrão foram comparadas pelo teste Ducan a 5\%. O período do parto ao primeiro estro pós-parto foi menor $(\mathrm{p}<0,05)$ tanto nas ovelhas que receberam suplementação alimentar como naquelas em que as crias tiveram amamentação controlada. Portanto, ovelhas da raça Santa Inês mantidas em pastagem nativa, suplementadas no pós-parto e com crias submetidas à amamentação controlada apresentam o primeiro estro pós-parto mais precoce.

Palavras-chave: amamentação contínua, amamentação controlada, anestro, ovino, suplementação alimentar

\section{Postpartum Estrus of Santa Inês Ewe}

Abstract: The return to the estrus of 60 Santa Inês sheep was studied from June to November of 2004 and 2005, in Embrapa Middle North Experimental Range, in Campo Maior-PI, located at 4 46' 59" S and $42^{\circ} 07^{\prime} 20^{\prime} \mathrm{W}$, in the Northeastern Region of Brazil. The completely randomized experimental design was used in a $2 \times 2$ factorial arrangement, factors being without alimentary supplementation $\mathrm{x}$ with alimentary supplementation and continuous $\mathrm{x}$ controlled suckling. The averages were compared by Ducan test at $5 \%$. The period from the birth to the first postpartum estrus was shorter $(\mathrm{p}<0.05)$ in the sheep receiving alimentary supplement as well as in those with lambs under controlled suckling.. Range maintained Santa Inês sheep, receiving alimentary supplement at the postpartum and with lambs under controlled suckling were earlier to present the first postpartum estrus.

Key words: alimentary supplementation, anestrus, continuous suckling, controlled suckling, sheep

\footnotetext{
${ }^{1}$ Parte da Tese de Doutorado do primeiro autor. Projeto financiado pelo BNB

${ }^{2}$ Pesquisador Embrapa Meio-Norte. E-mail: tleal@cpamn.embrapa.br (autor para correspondência)

${ }^{3}$ Professor da Universidade Estadual do Ceará
} 


\section{Introdução}

OestadodoPiauíé detentor do terceiromaiorrebanho ovino do Brasil e ainda detém todas as condições ambientais que favorecem o desenvolvimento da atividade, no entanto, a disponibilidade de carne ovina não supre sequer a demanda interna estadual. O sistema de exploração predominante no Nordeste do Brasil é o extensivo, onde os animais dependem exclusivamente da vegetação nativa, que sofre influência das épocas chuvosa e seca. Durante o período chuvoso, a alimentação disponível é abundante e de boa qualidade, enquanto que no período seco, a disponibilidade e qualidade da pastagem reduzem acentuadamente. Estas adversidades climáticas contribuem para tornar baixos os índices de desempenho produtivo e reprodutivo da ovinocultura.

Após o parto e com o início da lactação, os requerimentos nutricionais das ovelhas aumentam significativamente e, caso o suprimento alimentar não seja atendido, as matrizes reduzem suas reservas calóricas, resultando em diminuição da produção de leite e ocorrência de anestro. Segundo GonzálezStagnaro (1993) a diminuição das reservas corporais afetou as funções produtivas e reprodutivas de forma que animais com baixa condição corporal condicionaram a atividade sexual à chegada das chuvas, devido ao crescimento dos pastos, ou necessitarem de suplementação alimentar.

Além dos problemas de ordem nutricional, no início da lactação, os hormônios hipofisários estão mais dirigidos para a síntese e secreção de leite, do que para a restauração da atividade cíclica das fêmeas ovinas, resultando em um período de anestro (Maia, 1996).

O objetivo deste trabalho foi avaliar o retorno ao estro pós-parto em ovelhas da raça Santa Inês, com ou sem suplementação alimentar e cujas crias foram expostas às amamentações contínuas ou controladas.

\section{Material e Métodos}

O experimento foi realizado na Fazenda da Embrapa Meio-Norte, em Campo Maior, PI, no período de junho a novembro (meses em que há escassez de chuvas) dos anos de 2004 e 2005. A estação experimental localiza-se a $4^{\circ} 47^{\prime}$ de latitude Sul e $42^{\circ} 08^{\prime}$ de longitude oeste, com altitude de $120 \mathrm{~m}$ acima do nível do mar, em área de vegetação campestre típica da criação de ovinos do Piauí. O tipo climático é Aw', com pluviosidade média anual de $1.200 \mathrm{~mm}$, distribuídos de janeiro a início de maio, temperatura média anual de $27^{\circ} \mathrm{C}$ e umidade relativa média de 70,34\%.

O mesmo lote de 60 ovelhas, pluríparas e recémparidas, da raça Santa Inês, foi utilizado nos dois anos de experimento (2004 e 2005). Todas as matrizes e crias permaneceram juntas até o $14^{\circ}$ dia de vida e a partir do $15^{\circ}$ dia os cordeiros com suas respectivas mães foram distribuídos eqüitativamente em quatro lotes experimentais. No momento da distribuição dos animais em lotes, levou-se em consideração o peso corporal da matriz e o tipo de parto (simples ou duplo). O esquema de distribuição dos tratamentos foi o seguinte: T1 - matrizes sem suplementação alimentar no pós-parto + amamentação contínua; T2: matrizes sem suplementação alimentar no pósparto + amamentação controlada; T3: matrizes com suplementação alimentar no pós-parto + amamentação contínua; T4: matrizes com suplementação alimentar no pós-parto + amamentação controlada.

O controle da amamentação (ACT), iniciado a partir do $15^{\circ}$ dia pós-parto, consistiu em duas amamentações diárias, das 7:00 às 7:30 e das 16:00 às 16:30 horas. Já os lotes matrizes e crias submetidos à amamentação contínua (ACN), foram mantidos em pastagem nativa das 7:30 às 16:00 horas, quando eram recolhidas ao aprisco. As crias submetidas ao 
Rev. Cient. Prod. Anim., v.12, n.2, p.158-161, 2010

Tabela 1 - Intervalos médios (dias) entre o parto e o primeiro estro pós-parto (IPPE) \pm desvios-padrão em ovelhas da raça Santa Inês, conforme o manejo da alimentação e da amamentação. SS = sem suplementação; CS = com suplementação

\begin{tabular}{cccc}
\hline \multicolumn{4}{c}{ IPPE (dias) \pm desvios padrão } \\
\hline \multirow{2}{*}{ Suplementação } & \multicolumn{3}{c}{ Amamentações } \\
\cline { 2 - 4 } & Contínua & Controlada & Médias \\
SS & $150,95 \pm 29,52$ & $134,42 \pm 34,46$ & $142,69^{\mathrm{a}}$ \\
CS & $80,29 \pm 26,62$ & $68,75 \pm 29,62$ & $74,52^{\mathrm{b}}$ \\
Médias & $1115,62^{\mathrm{A}}$ & $101,59^{\mathrm{B}}$ & \\
\hline
\end{tabular}

Para cada variável, médias seguidas da mesma letra minúscula nas colunas e maiúsculas nas linhas, não diferem pelo teste Ducan a $5 \%$.

tratamento ACT permaneceram confinadas durante todo o período experimental.

Para o grupo de matrizes que receberam suplementação alimentar (CS), foram oferecidas 300 $\mathrm{g} /$ matriz/dia de uma mistura dietética com $18 \%$ de proteína bruta $(\mathrm{PB})$ na fase de pós-parto, do primeiro ao $84^{\circ}$ dia.

Todos os animais receberam água e sal mineral à vontade. As ovelhas foram colocadas com rufiões do primeiro ao $200^{\circ}$ dia aproximadamente do período pós-parto, como mecanismo de auxilio de identificação do estro. Os rufiões tiveram a região do esterno untada com uma mistura de tinta em pó (xadrez) e graxa na proporção de 1:4, com o objetivo de marcar a região lombar da fêmea montada e que apresentasse estro.

O delineamento experimental empregado foi inteiramente casualizado com arranjo fatorial $2 \times 2$ (SS x CS e ACN x ACT), cada animal constituindo uma repetição. Os dados foram analisados utilizando o procedimento GLM (General Linear Model) pelo "software" SAS (Statystical Analysis System), através do método de análise de variância (ANOVA). As médias foram comparadas pelo teste de Ducan a 5\%.

\section{Resultados e Discussão}

As médias de intervalos entre o parto e o primeiro estro pós-parto (IPPE) das ovelhas (Tabela 1), mostraram que houve efeito significativo $(p<0,05)$ do manejo da alimentação, sendo que as fêmeas suplementadas tiveram um IPPE mais curto $(p<0,05)$. Achados semelhantes foram encontrados por Andrioli et al. (1989) e Leal e Reis (1997). A subnutrição, segundo McShane et al. (1993), eleva a concentração do neuropeptídeo Y no hipotálamo, diminuindo a secreção de GnRH e, conseqüentemente, a de LH.

Os tipos de amamentação (contínua ou controlada) também influenciaram na duração do IPPE. Ovelhas cujas crias foram submetidas à amamentação contínua tiveram um IPPE mais longo $(p<0,05)$ do que as ovelhas cujas crias foram submetidas à amamentação controlada. A estimulação da glândula mamária em ovelhas, no momento da sucção, induz a liberação de ß- endorfinas e desencadeiam ao mesmo tempo um descarga de prolactina, inibindo portanto a descarga de LH. Desta forma, a amamentação retarda a atividade hipotalámico-hipofisária (Delouis e Richard, 1991).

\section{Conclusões}

Ovelhas da raça Santa Inês criadas em pastagem nativa no Nordeste do Brasil e que recebem suplementação alimentar apresentam o primeiro estro pós-parto mais precoce do que aquelas não suplementadas. Desta forma, a suplementação oferece condições para que a fêmea possa produzir maior número de crias/ano;

A amamentação controlada proporciona às ovelhas um retorno ao estro pós-parto mais precocemente, 
favorecendo a antecipação de uma nova concepção, LEAL, T. M.; REIS, J. C. Efeitos da complementação reduzindoo intervaloentrepartose, conseqüentemente, alimentar no pós-parto sobre o intervalo partomelhorando a eficiência reprodutiva e produtiva dos primeiro estro de cabras sem raça definida (SRD). ovinos.

In: REUNIÃO ANUAL DA SOCIEDADE BRASILEIRA DE ZOOTECNIA, 24, 1997, Juiz de

\section{Literatura Citada}

ANDRILOLI, A.; SIMPLÍCIO, A. A.; MACHADO, R. Comportamento reprodutivo pós-parto em cabras Sem Raça Definida mantidas em pastagem nativa no nordeste do Brasil. Sobral: EMBRAPA- CNPC, 1989. 18 p. (EMBRAPA-CNPC. Boletim de pesquisa, 14).

DELOUIS, C.; RICHARD, P. La lactation. In: THIBAULT, C.; LEVASSEUR, M. C. La reproduction chez les mammifères et l'homme. Paris: Edition Marketing, p. 487-514, 1991.

GONZALEZ-STAGNARO, C. Comportamiento reproductivo de ovejas y cabras tropicales. Revista Científica, FCV-LUZ, v. 3, n. 3, p. 173-195, 1993. Fora. Anais... Juiz de Fora: Sociedade Brasileira de Zootecnia, 1997, p. 358-360.

MAIA, M. da S. Influência do tipo de amamentação sobre a atividade ovariana pós-parto de cabras Canindé e sobre o desempenho dos cabritos, no semi-árido do Rio Grande do Norte. Recife: Universidade Federal Rural de Pernambuco, 1996. 113 p. (Dissertação de mestrado).

McSHANE, T.M., PETERSEN, S. L., McCRONE, S., KEISLER, D. H. Influence of food restriction on neuropeptide $\mathrm{Y}$, proopiomelanocortin and luteinizing hormone - releasing hormone gene expression in sheep hypotalamic. Biology of Reproduction, v.49, p.831-839, 1993. 